
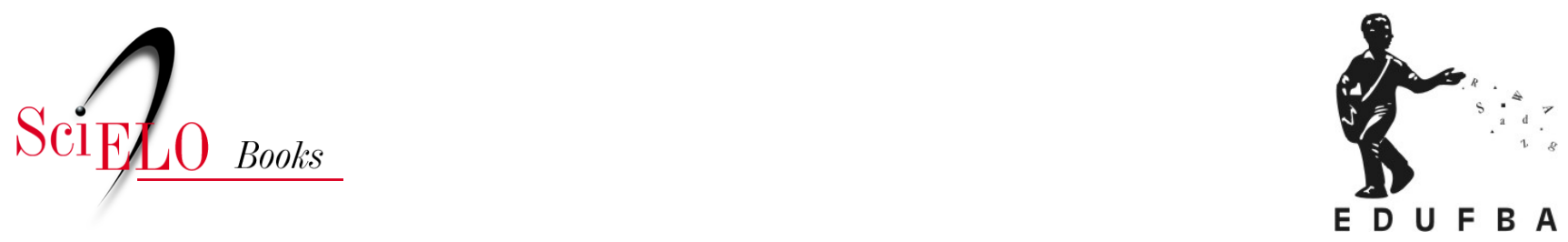

\title{
8 Tribo Hyalideae Panero
}

\author{
Nádia Roque
}

ROQUE, N. Tribo Hyalideae Panero. In: ROQUE, N. TELES, A.M., and NAKAJIMA, J.N., comp. A família Asteraceae no Brasil: classificação e diversidade [online]. Salvador: EDUFBA, 2017, pp. 73-75. ISBN: 978-85-232-1999-4. https://doi.org/10.7476/9788523219994.0010.

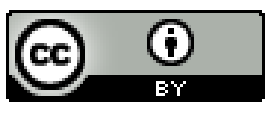

All the contents of this work, except where otherwise noted, is licensed under a Creative Commons Attribution 4.0 International license.

Todo o conteúdo deste trabalho, exceto quando houver ressalva, é publicado sob a licença Creative Commons Atribição $\underline{4.0}$.

Todo el contenido de esta obra, excepto donde se indique lo contrario, está bajo licencia de la licencia Creative Commons Reconocimento 4.0. 


\section{TRIBO HYALIDEAE PANERO}

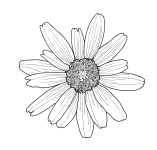

Nádia Roque

Hyalideae, juntamente com a tribo Wunderlichieae, compõem a subfamília Wunderlichioideae, estabelecida a partir de estudos filogenéticos moleculares (FUNK et al. 2009; PANERO; FUNK, 2007, 2008). A tribo inclui 2 clados, os gêneros sul americanos Hyalis D. Don (2 spp.) e Ianthopappus Roque \& D.J.N. Hind (1 sp.), que são nomeados como clado Hyalis, e os gêneros asiáticos, Leucomeris D. Don (2 spp.) e Nouelia Franch. (1 sp.), referidos como clado Leucomeris. Esses gêneros foram considerados parte ou próximos de Gochnatia (FREIRE; KATINAS; SANCHO, 2002; ROQUE; HIND, 2001), com base no apêndice da antera apiculado e ramos do estilete glabros.

Entretanto, o apêndice do conectivo agudo, cipsela 10-costada, 100150(200) elementos do pápus arranjados em 3-4(-5) séries provêm a hipótese de relação de parentesco entre Stifftioideae e Wunderlichioideae (tribos Hyalideae e Wunderlichieae), corroborando a segregação daqueles gêneros da tribo Gochnatieae (FUNK et al., 2014; ROQUE; FUNK 2013).

\section{Descrição}

Subarbustos, arbustos ou pequenas árvores. Folhas alternas, lâmina foliar linear a largamente obovada, inteira a levemente serreada, serícea a argêntea na face abaxial. Capitulescência em cimeiras paniculiformes, raramente corimbiformes, ou capítulos solitários, discoides ou radiados, homógamos ou heterógamos; receptáculo plano, epaleáceo; invólucro campanulado, brácteas involucrais 5-10 séries, imbricadas, graduadas, to- 
mentosas, seríceas ou glabrescentes. Flores marginais, quando presentes, bilabiadas, bissexuais ou pistiladas (Ianthopappus), flores do disco actinomorfas, 5 lobos revolutos, alvas ou púrpura; estames com apêndice do conectivo da antera apiculado, base caudada; estilete com ramos curtos a longos, arredondados, glabros. Cipselas cilíndricas a obovóides, 10-costadas, carpopódio anular, simétrico; pápus cerdoso, 3-4(-5) séries, (90)100-200 elementos cerdosos, cerdas de diferentes tamanhos, estramíneas ou púrpura (Ianthopappus).

A tribo Hyalideae está representada no Brasil por apenas um gênero monoespecífico, Ianthopappus corymbosus (Less.) Roque \& D.J.N. Hind, cuja distribuição ocorre no extremo sul do Brasil (Rio Grande do Sul), Argentina e Uruguai. (ROQUE; HIND, 2001) A espécie pode ser reconhecida pelo hábito subarbustivo, folhas sésseis, lâmina foliar orbicular, argêntea na face abaxial, venação actinódroma, capítulos radiados, heterógamos e pápus púrpura (Figura 5E).

\section{Literatura recomendada}

FREIRE, S. E.; KATINAS, L.; SANCHO, G. Gochnatia (Asteraceae, Mutisieae) and the Gochnatia complex: taxonomic implications from morphology. Annals of Missouri Botanical Garden 89: 524-550, 2002.

FUNK, V. A. et al. Mutisieae sensu stricto (Mutisioideae sensu stricto). In: FUNK, V. A. et al. (Ed.). Systematics, Evolution and Biogeography of Compositae. Vienna: IAPT, 2009. p. 171-189.

PANERO, J. L.; FUNK, V. A. New infrafamilial taxa in Asteraceae. Phytologia, [S.1.], v. 89, n. 3, p. 356-360, 2007.

PANERO, J. L.; FUNK, V. A. The value of sampling anomalous taxa in phylogenetic studies: major clades of the Compositae revealed. Molecular Phylogenetics and Evolution, Orlando, v. 47, n. 2, p. 757-782, 2008.

FUNK, V. A. et al. A phylogeny of the Gochnatieae: understanding a critically placed tribe in the Compositae. Taxon, Utrecht, v. 63, n. 4, p. 859888, 2014. 
ROQUE, N.; FUNK, V. A. Morphological characters add support for some members of the basal grade of Asteraceae. Botanical Journal of the Linnean Society, London, v. 171, n. 3, p. 568-586, 2013.

ROQUE, N.; HIND, D. J. N. Ianthopappus, a new genus of the Tribe Mutisieae (Compositae). Novon, Saint Louis, v. 11, n. 1, p. 97-101, 2001. 